\title{
Coronary revascularisation: why do rates vary geographically in the UK?
}

\author{
Health Services \\ Research Unit, \\ Department of Public \\ Health and Policy, \\ London School of \\ Hygiene and Tropical \\ Medicine, Keppel \\ Street, London WC1E \\ 7HT \\ N Black \\ $S$ Langham \\ M Petticrew \\ Correspondence to: \\ Dr N Black. \\ Accepted for publication \\ January 1995
}

\begin{abstract}
Objective - To explain the reasons for geographical variation in the use of coronary revascularisation in the United Kingdom. Design - This was a cross sectional ecological study.

Setting - NHS and independent hospitals performing coronary revascularisation for the 11.6 million residents of the south east Thames, East Anglian and north western health regions in England plus Greater Glasgow, Lanarkshire, Ayr and Arran health boards in Scotland were included. Subjects - All residents aged $\geq 25$ years in 1992-93 who underwent coronary artery bypass grafting (CABG) or percutaneous transluminal coronary angioplasty (PTCA) in either the public or private sector were included.

Main measures - Crude and age-sex standardised intervention rates for residents of the 42 constituent districts and boards were determined. Variation was measured using the systematic component of variation.

Results - Considerable systematic variations in district rates of CABG and PTCA existed. These variations mostly arose from differences in supply factors. Higher rate districts were characterised by being close to a regional revascularisation centre and having a local cardiologist. Demand factors such as the level of need in the population (measured by coronary heart disease mortality) and the lack of use of alternative treatments not only failed to explain the observed variation but were inversely associated with the rate of intervention - an example of the inverse care law. The finding that the residents of more socially deprived districts experienced higher intervention rates was probably subject to confounding due to their close proximity to specialist centres.

Conclusions - If greater geographical equity of use for the same level of need is to be achieved, attention must be paid to the supply factors that determine levels of utilisation. As responsibility for purchasing these procedures is decentralised, utilisation might become even more unequal.
\end{abstract}

\section{( $(\mathcal{E}$ Epidemiol Community Health 1995;49:408-412)}

Variations between places in the rate of use of health services have been shown for a wide range of interventions. ${ }^{1}$ These variations have been found in many countries, regardless of the way the health services are funded or or ganised. ${ }^{2}$ Differences in utilisation rates may result from statistical artifacts (such as data errors and random variation), from variation in demand (such as differences in morbidity and people's expectations), and from variation in supply (such as the availability of facilities and clinicians' judgments). ${ }^{3}$ The relative importance of each factor will depend partly on the size of the populations being compared For example, an individual hospital doctor could influence a district rate but would be unlikely to have a noticeable impact on a regional rate. Studies have found that, having taken statistical and demographic factors into account, the availability of facilities and the judgments of clinicians seem to exert the greatest influence on utilisation rates. ${ }^{4-7}$

Wide variation has been reported in the utilisation rates of coronary artery bypass grafting (CABG) and percutaneous translumina coronary angioplasty (PTCA) between region of the United Kingdom ${ }^{89}$ within North America, ${ }^{10-12}$ and between countries in Europe. ${ }^{13}$ Only four studies, however, have attempted to explain why such differences exist, and these limited their enquiries to a restricted number of possible determinants. The only factors to have been shown to be associated with the utilisation rate have been the availability of facilities, in particular catheterisation laboratories, ${ }^{13-15}$ and the distance patients live from these facilities. ${ }^{16}$ No association has been found with the rate of use of alternative therapies and the level of coronary heart disease morbidity in the population. ${ }^{13151718}$

In an attempt to understand the reasons for variation in revascularisation rates in the UK, some preliminary analyses were undertaken on 1991-92 data and reported in a Clinical Standards Advisory Group report on the availability of and access to CABG and PTCA. ${ }^{19}$ This paper describes more detailed analyses of the variations that occurred during 1992-93.

\section{Methods}

Data were collected for the residents of three English health regions (south east Thames, East Anglia, and north western) and three Scottish health boards (Greater Glasgow, Lanarkshire, Ayr and Arran) for 1992-93. For the purposes of this paper, the area covered by the three Scottish boards are referred to as a "region". The study regions covered 11.6 million people in $1992(20 \%$ of the UK population) and were selected to ensure representation of historical levels of provision and population density. All residents who 
underwent either CABG (OPCS codes K4046) or PTCA (K49-50) without any other procedure were included.

All NHS and private hospitals that provided revascularisation services for the residents of the four regions were identified by obtaining aggregate data directly from cardiology and cardiac surgery departments in every provider in the UK performing coronary revascularisation. Detailed data on individual patients were then collected from all the major providers such that at least $97 \%$ of all procedures carried out on the study populations were included. This meant obtaining data from 10 NHS and six private hospitals within the regions and six NHS hospitals in other regions. Private hospitals outside the study regions made little contribution in three of the regions and could therefore be safely ignored. In the south east Thames region, however, we were unable to obtain data from four private hospitals which might have made a significant contribution, so analyses for that region had to be restricted to NHS patients.

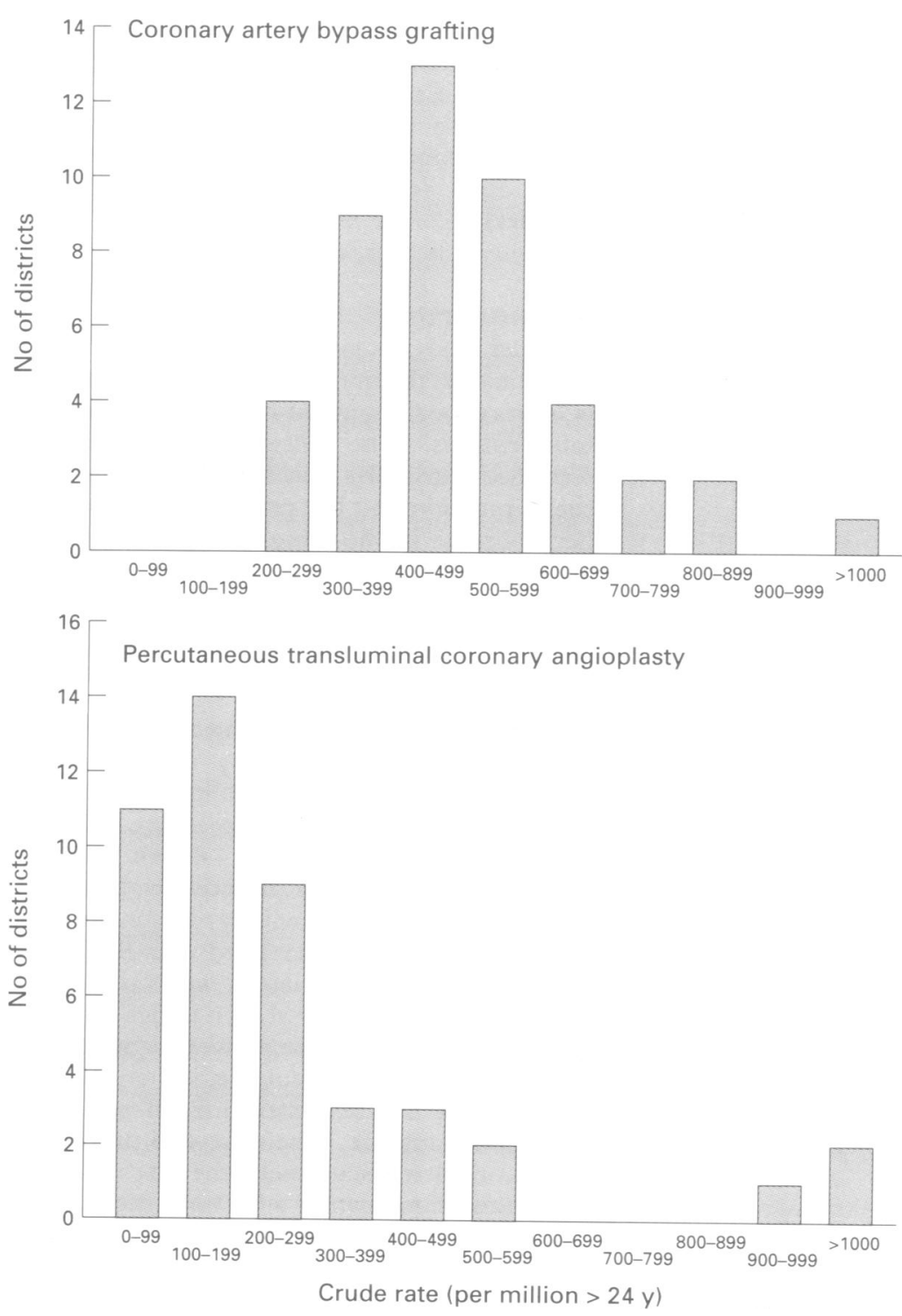

Figure 1 Distribution of district rates of coronary artery bypass grafting and percutaneous transluminal coronary angioplasty. (Crude number of NHS cases per million
population aged $\geq 25$ years, 1992-93)
The following data on each patient were obtained from all 22 hospitals: sex, age, procedure, provider unit, and district/board of residence. Data were obtained from a variety of sources including clinical computer systems, manual registers, card indexes, clinicians' summary charts, theatre registers, and case notes. Often, patients' addresses had first to be manually post-coded before a health district code could be identified. Data were entered into a $d B A S E$ file and transferred to a spreadsheet using Lotus 123. Complete data were obtained for all variables except age. Patients whose age was unknown (about $2 \%$ ) were distributed across the age range according to the age distribution of those patients whose ages were known.

District utilisation rates directly standardised (using the total population of the four regions derived from the 1991 decennial census) for age and sex (25-44 years, 45-54, 55-64, 65-74, $\geq 75$ ) were calculated for each procedure. The amount of variation between health districts in each region was assessed by means of the systematic component of variation (SVC). This takes into account differences in the mean regional rate and differences in the sizes of the district populations, both of which will influence the amount of random variation. ${ }^{20}$ Indicators of coronary heart disease morbidity used were district standardised mortality ratios (ICD $410-414 ; 1990-91$ ) and both the Jarman $^{21}$ and Department of the Environment ${ }^{22}$ social deprivation indices for 1990-91. The amount of association between these proxy measures of need and utilisation rates was assessed using Pearson correlation coefficients. The same was used to assess association between the district rate of CABG and that of PTCA. Association between the availability of NHS facilities in a region (obtained directly from the provider units) and the regional rate was assessed by means of a scatterplot. As only three regions were included, data for three previous years in those regions were also included but no correlations were calculated as the resulting 12 data points were not independent of one another. The effect of distance from facilities was assessed visually by mapping the district rates. Association between district rates and the existence of a local cardiologist was tested for using ANOVA for $\mathrm{CABG}$ as the variances were homogenous with $95 \%$ confidence and the data were normally distributed. The Kruskal-Wallis test was used for PTCA as the variances differed $(p=$ $0 \cdot 0002)$.

\section{Results}

AMOUNT OF VARIATION IN NHS CRUDE RATES Rates of CABG varied between districts almost fivefold from 226 to 1015 per million population aged 25 years or more (fig 1). PTCA rates varied much more, from 12 to 1450 per million. The greater degree of variation for PTCA was seen by comparing the SCV for the two procedures for each region (Table 1). Apart from in Greater Glasgow (which comprised only three districts) the SCV for PTCA was much higher than that for CABG. 
Table 1 Extent of interdistrict variation of crude and age-sex standardised revascularisation rates within each region measured by the systematic component of variation (SVC). NHS and private cases included except in south east Thames region (NHS only).

\begin{tabular}{lcccc}
\hline \multicolumn{5}{c}{ Health region } \\
\cline { 2 - 5 } & E Anglian & $N$ western & S E Thames & G Glasgow \\
\hline Coronary artery bypass grafting & & & & \\
NHS crude rates & $4 \cdot 6$ & $12 \cdot 1$ & $5 \cdot 7$ & $6 \cdot 6$ \\
NHS + private crude rates & $5 \cdot 6$ & $9 \cdot 4$ & {$[5 \cdot 7]$} & $8 \cdot 1$ \\
NHS + private standardised rates & $9 \cdot 8$ & $12 \cdot 0$ & $12 \cdot 5$ & $8 \cdot 1$ \\
Percutaneous transluminal coronary angioplasty & & & \\
NHS crude rates & $14 \cdot 8$ & $59 \cdot 9$ & $50 \cdot 4$ & $2 \cdot 9$ \\
NHS + private crude rates & $21 \cdot 8$ & $41 \cdot 0$ & {$[50 \cdot 4]$} & $3 \cdot 4$ \\
NHS + private standardised rates & 23.7 & $44 \cdot 7$ & $60 \cdot 1$ & $4 \cdot 1$ \\
\hline
\end{tabular}

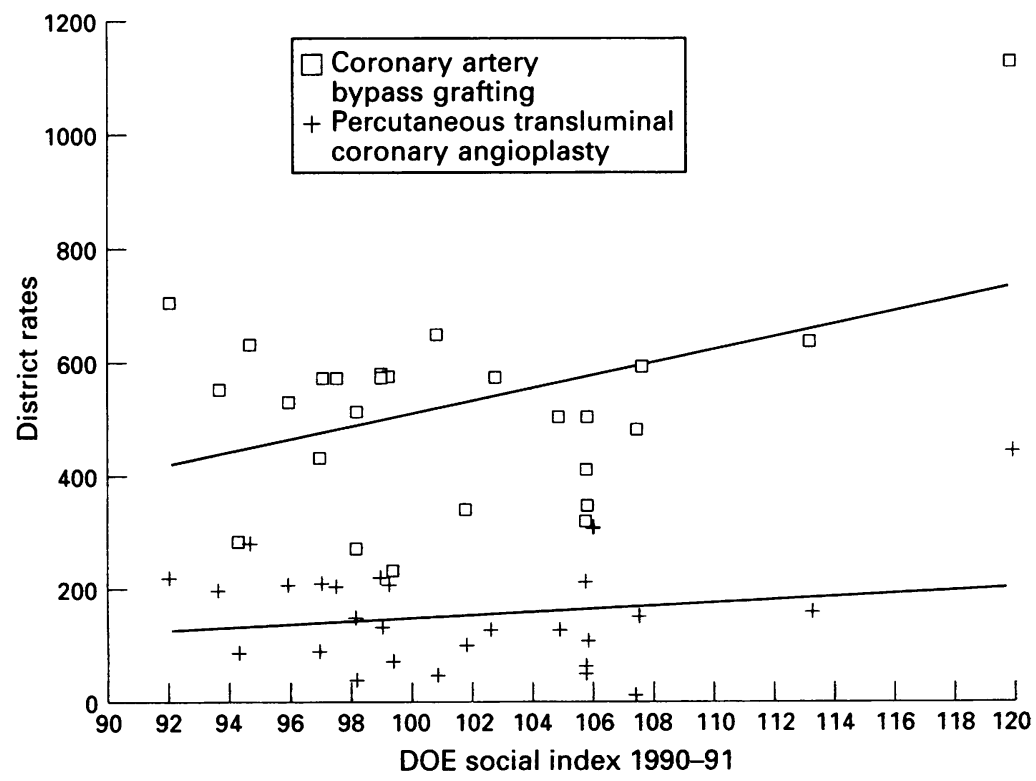

Figure 2 Relationship between district age-sex standardised rates for coronary artery bypass grafting and percutaneous transluminal coronary angioplasty (NHS and private cases per million population aged $\geq 25$ years, 1992-93) with Department of the Environment social index (1990-91)

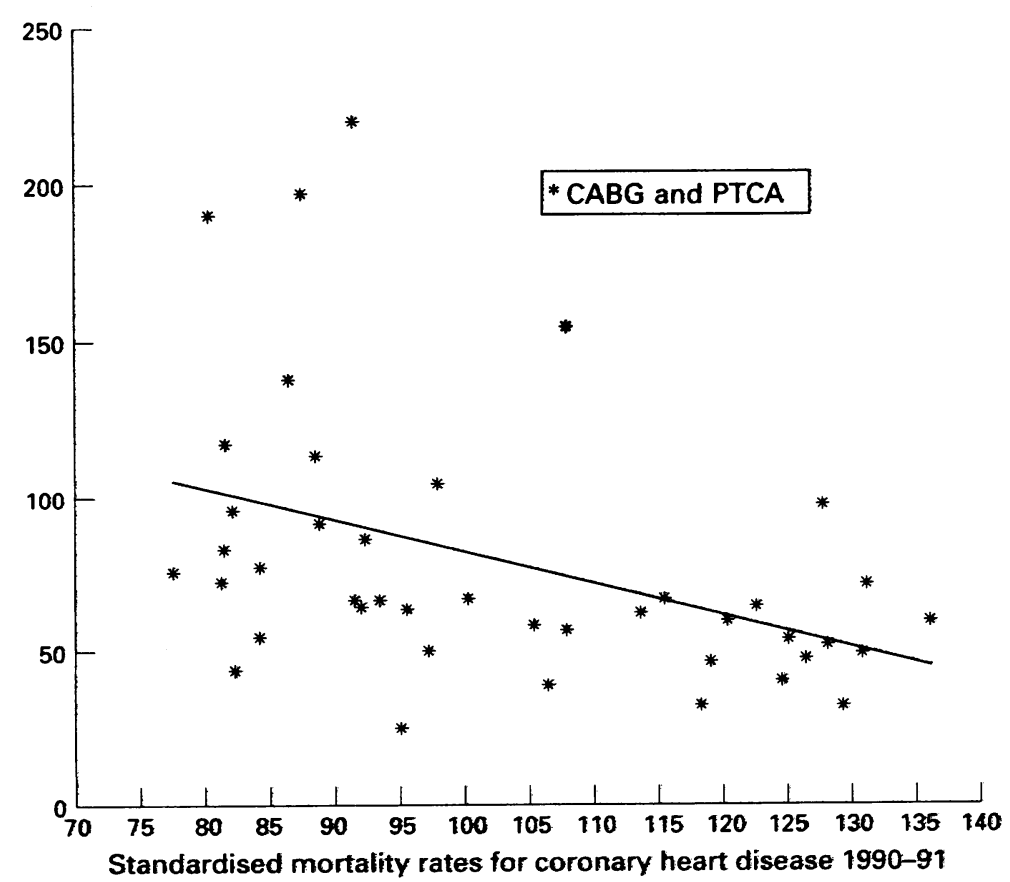

Figure 3 Relationship between district utilisation rates for revascularisation (1992-93) with standardised mortality ratios for coronary heart disease (1990-91).
STATISTICAL REASONS

The first possible explanation considered was that data might have been missing for those districts with the lowest rates as a result of incomplete data collection in the hospitals, incorrect clinical coding, or failure to allow for cross boundary flows. However, the data were collected directly from clinical departments rather than relying on hospital information systems so we are confident that few if any cases were missed and that the coding of operative procedures was accurate. By checking all hospitals in the UK that perform revascularisation for NHS patients, we know we included at least $97 \%$ of patients resident in the study districts irrespective of where they were treated.

Next, the extent to which differences between districts in the use of the private sector was considered. While the addition of private cases made little difference to the range of district rates of CABG, it reduced the amount of dispersion. Thirteen (43\%) of the districts had rates of 500-599 per million. Comparison with the distribution of NHS rates shown in figure 1 is difficult as data from independent hospitals were not available for south east Thames region. The impact on the SCV of including private cases was slight, increasing the value in East Anglian and Greater Glasgow but reducing it in north western (table 1). All subsequent analyses included private as well as NHS cases (except for data for south east Thames).

\section{DEMAND FACTORS}

The demand for any procedure depends on three factors: the normative need for treatment, people's expectations, and the use of alternative interventions. The normative need is determined partly by the age-sex structure of the population and the prevalence of coronary heart disease in the population. Direct standardisation for age and sex had no impact on the degree of variation, as has previously been shown. ${ }^{19}$ Indeed, the SCVs for age-sex standardised rates were larger than those for the crude rates (table 1 ).

As no accurate epidemiological data on disease prevalence exist, proxy measures were used: the standardised mortality ratio for coronary heart disease and two measures of social deprivation (which has been shown to be related to the prevalence of coronary heart disease $^{23}$ ). Age-sex standardised revascularisation rates were inversely correlated with SMRs but were positively correlated with social deprivation (examples are shown in figs 2 and 3 ). The correlation coefficients were significant at the $5 \%$ level for revascularisation with SMRs and one of the two measures of social deprivation (table 2). When the two procedures were considered separately, the rate of CABG correlated significantly with both measures of social deprivation and the rate of PTCA with SMRs. In other words, higher intervention rates were associated with districts with lower SMRs and with more deprived districts.

Demand for either CABG or PTCA could be affected by the use of the other procedure. 
Table 2 Relationship between district revascularisation rates and proxy measures of morbidity (correlation coefficients plus $95 \%$ confidence intervals)

\begin{tabular}{|c|c|c|c|}
\hline & Coronary artery bypass grafting & $\begin{array}{l}\text { Percutaneous transluminal } \\
\text { coronary angioplasty }\end{array}$ & Both \\
\hline $\begin{array}{l}\text { Standardised mortality ratio } \\
\text { Jarman social deprivation index* } \\
\text { Department of Environment social index* }\end{array}$ & $\begin{array}{c}-0.18(-0.46,0 \cdot 13) \\
0.52(0.26,0 \cdot 71) \\
0.52(0.25,0.71)\end{array}$ & $\begin{array}{c}-0.48(-0.68,-0.20) \\
0.11(-0.20,0.40) \\
0.13(-0 \cdot 18,0.42)\end{array}$ & $\begin{array}{c}-0.42(-0.64,-0.13) \\
(0.30(-0.01,0.55) \\
0.31(0.01,0.56)\end{array}$ \\
\hline
\end{tabular}

${ }^{*}$ Higher index scores represent greater deprivation

In practice, the opposite occurred. The regional age-sex standardised rates (NHS plus private) for CABG were highly correlated with those for PTCA (Pearson correlation coefficient $\mathbf{r}=$ $0 \cdot 81 ; 95 \%$ confidence interval (CI) $0 \cdot 63,0 \cdot 90$ ).

\section{SUPPLY FACTORS}

It was not possible to relate district utilisation rates to the availability of tertiary or specialist services as services are not specifically allocated to each district. It was possible, however, to relate regional rates to the availability of regional services. This showed that both CABG and PTCA rates correlated with consultant and non-consultant staffing levels (an example is shown in fig 4) but not with bed numbers. Generally the higher the staffing level, the higher the utilization rate, though it was also apparent that one region (north western) achieved a lower level of activity than would have been expected for its consultant staffing level.

Two indicators of service availability at district level were used. Firstly, the influence of the distance of the district from the main specialist centre was investigated by mapping. This showed that, in general, the closer a district was to a centre the higher was the rate.

The second indicator used was whether or not a district had a local cardiologist (defined as at least six sessions from a physician with specialist training in cardiology and who spends at least $40 \%$ of his or her time practising car-

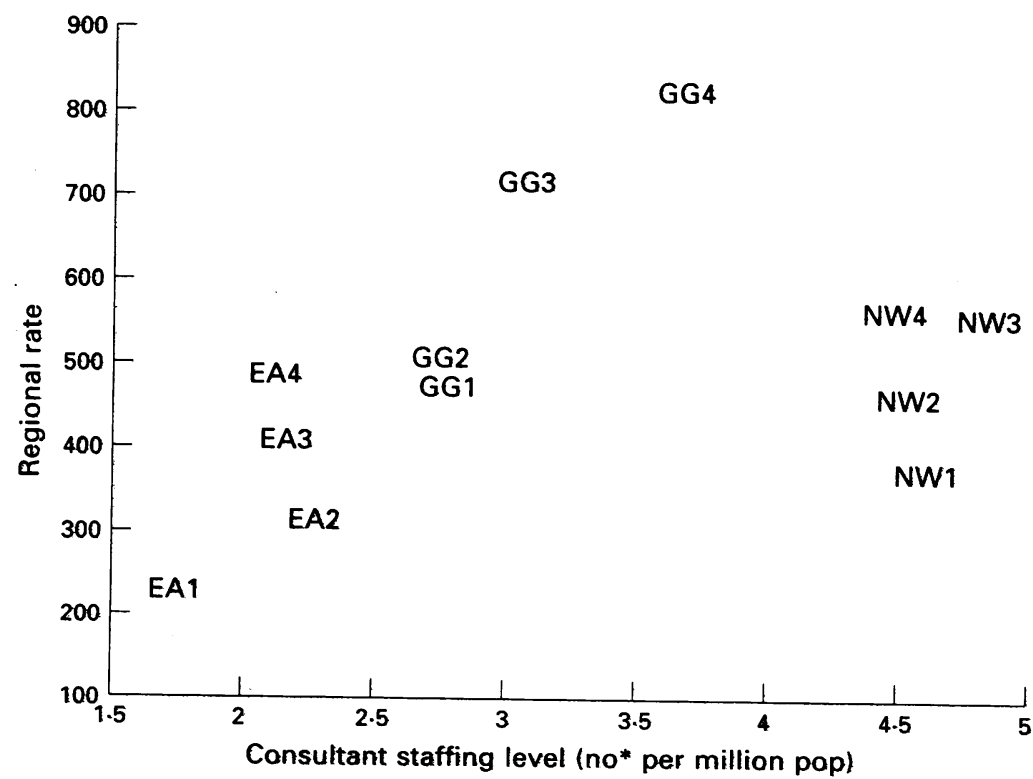

Figure 4 Age-sex standardised rate (NHS and private cases per million population aged $\geq 25$ years) for coronary artery bypass grafting for three study regions (East Anglia $(E A)$, north western (NW), and Greater Glasgow (GG)) for the years 1987-88 (1), $1989-90$ (2), 1991-92 (3), and 1992-93 (4) in relation to consultant staffing levels in regional centres. ${ }^{*}$ Number of full time equivalents per million pop. diology). Of the seven districts which did not have a cardiologist, the mean rate for CABG was 378 per million compared with 535 per million for the other 38 districts $(F$ statistic $=$ $4 \cdot 3 ; p=0.041$ ). The equivalent rates for PTCA were 89 and 306 per million (Kruskal-Wallis statistic $=7 \cdot 25 ; \mathrm{p}=0 \cdot 007$ ).

\section{Discussion}

Rates of coronary revascularisation vary geographically within the UK principally because of differences in the supply of services. This study has shown that significant differences in regional and district rates persist even when statistical and demand factors have been taken into account. These geographical differences can partly be explained by differences in the availability of specialist revascularisation services, such as levels of medical staffing in regional centres, the presence of a local cardiologist and the distance from a specialist centre. As such our results are consistent with previous findings. ${ }^{13-15}$

Any remaining differences may be due to variation in clinical judgment about the appropriate indications for intervention. As a standard method for recording patients' clinical indications for treatment is not employed routinely in the $\mathrm{UK}$, it was not possible in this study to investigate how clinical judgment varied between the specialist centres. The widespread adoption of a validated case-mix measure that considered a patient's age, sex, disease severity, and comorbidity would not only enable geographical differences in access to services to be investigated and monitored but would also allow useful comparisons of outcome to be made. While such a development would increase our understanding of the contribution of the clinical judgment of specialists to determining utilisation rates, much of the variation in use may have its origins in differences in the opinions of general practitioners. There is therefore also a need to study decision making in primary care.

Our results are consistent with another previously reported finding that utilisation is not related to the rate of use of alternative therapies. ${ }^{15}$ Indeed, we found that districts with a high rate of use of one revascularisation procedure were likely to also have a high use of the other. In other words, there was no evidence of the use of one procedure compensating for lack of use of the other.

With regard to the influence of the level of morbidity in the population, our data were conflicting. Districts with high apparent levels of need, as measured by coronary heart disease mortality, made significantly less use of revascularisation services than populations with 
low levels of need. This seemed to be an example of the "inverse care law". ${ }^{24}$ However, this finding seemed to conflict with the finding that districts with high levels of social deprivation made more use of services than less deprived districts. This association may well have been confounded by distance from the specialist centre - the more deprived districts tend to be in inner city areas where many of the specialist centres are located. This view is supported by the observation that in East Anglian region where the only NHS specialist centre is located in a relatively affluent district (Huntington) which enjoys the highest intervention rate in the region.

This study has taken a cross sectional look at variation between districts. It is perhaps to be expected that large differences would be found in the rates of PTCA given its recent introduction as a new technology and the provision of $C A B G$ is still increasing as additional centres are established and existing ones expand. Given these continued developments, a reduction in the extent of variation between districts might be expected to occur over the coming years as the availability of services increases (though differences in clinical judgment would continue to ensure some variation persisted). However, as the purchasing of these procedures is decentralised from regions to consortia of districts to individual districts and finally to general practitioners it is quite likely that variations in use will increase rather than decrease.

Data for this paper were collected while preparing a report for a working group of the Access and Availability Committee of the Clinical Standards Advisory Group. We are grateful to all members of the working group (Sir Terence English, $\mathrm{Mr}$ John Parker, Dr John Perrins, and Dr Gordon Pledger) and Paul Marshall $(\mathrm{DoH})$ for their comments and support. The work was funded by the Department of Health. The views expressed in this paper are those of the authors and do not necessarily reflect those of the working group or the DoH.

1 Wennberg JE. Dealing with medical practice variations: a proposal for action. Health Affairs 1984;3:6-32.

2 Ham C ed. Health care variations: assessing the evidence. King's Fund Institute, London, 1988
3 McPherson K, Strong PM, Epstein A, Jones L. Regional variations in the use of common surgical procedures: within and between England and Wales, Canada and the United States of America. Soc Sci Med 1981;15A:273-88.

4 Vayda $E$. A comparison of surgical rates in Canada and in England and Wales. New Engl 7 Med 1973;289:1224-9.

England and Wales. New Engl f Med 1973;289:1224-9. rates and their relationship with resource supply and need. rates and their relationship with

6 Black NA. Geographical variations in the use of surgery for glue ear. $\mathcal{f} R$ Soc Med 1985;78:641-8.

7 Roos LL. Supply, workload and utilization: a populationbased analysis in rural Manitoba. Am f Public Health 1983; 73:414-21.

8 English TAH, Bailey AR, Dark JF, Williams WG. The UK cardiac surgical register, 1977-82. BMF 1984;289:1205-8.

9 Working Party of the British Cardiac Society. Coronary angioplasty in the United Kingdom. Br Heart 7 1991;66: 325-31.

10 Naylor CD, Ugnat AM, Weinkauf D, Anderson GM, Wielgosz A. Coronary artery bypass grafting in Canada: what is its rate of use? which rate is right? Can Med Assoc $\mathcal{f} 1992 ; 146: 851-9$.

11 Higginson LAJ, Cairns JA, Keon WJ, Smith ER. Rates of cardiac catheterization, coronary angioplasty and openheart surgery in adults in Canada. Can Med Assoc $₹$ 1992; 146:921-5.

12 Anderson GM, Grumbach K, Luft HS, Roos LL, Mustard C, Brook R. Use of coronary artery bypass surgery in the United States and Canada. Influence of age and income. FAMA 1993;269:1661-6.

13 Van den Brand $M$ and the European Angioplasty Survey Group. Utilization of coronary angioplasty and cost of angioplasty disposables in 14 western European countries. Eur Heart $\mathcal{f}$ 1993;14:391-7.

14 Chamberlain D, Pentecost B, Revel K, et al. Staffing in cardiology in the United Kingdom 1990. Br Heart $\mathcal{F} 1991$ 66:395-404.

15 Kuhn E, Hartz A, Baras M. Correlation of rates of coronary artery bypass surgery and angioplasty among 305 SMSAs for Medicare patients. Proceedings of the 10th Anmual MAs

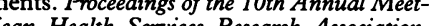
ing of the American Health Services Research Association. Washington DC, 1993.

16 Findlay IN, Cunningham D, Dargie HJ. The effect of cardiac catheterization facilities on the rate of coronary bypass grafting in Scotland. Br Heart $\mathcal{F}$ 1992;68:69.

17 Anderson GM, Lomas J. Regionalization of coronary arter bypass surgery. Effects on access. Med Care 1989;27: 288-96.

18 Roos LL, Sharp SM. Innovation, centralization, and growth. Coronary artery bypass graft surgery in Manitoba. Med Care 1989;27:441-52.

19 Clinical Standards Advisory Group. Access to and availability of connary artery bypass grafting and coronary angioplasty. HMSO, London 1993.

20 McPherson K, Wennberg JE, Hovind OB, Clifford P. Smallarea variations in the use of common surgical procedures: an international comparison of New England, England and Norway. New Engl f Med 1982;307:1310-14.

21 Jarman B. Underprivileged areas: validation and distribution of scores. BMF 1984;289:1587-92.

22 Department of the Environment. Urban deprivation. In formation note no 2 . London: Inner Cities Directorate,

23 Rose G, Marmot MG. Social class and coronary heart disease. Br Heart $\mathcal{F}$ 1981;45:13-19.

24 Hart JT. The inverse care law. Lancet 1971;i:405-12. 